\title{
THE
}

UNIVERSITY

University of Rhode Island

OF RHODE ISLAND

DigitalCommons@URI

5-5-2015

\section{Efficient Extraction and Detection of Aromatic Toxicants from Crude Oil and Tar Balls Using Multiple Cyclodextrin Derivatives}

Nicole Serio

University of Rhode Island

Mindy Levine

University of Rhode Island, m_levine@uri.edu

Follow this and additional works at: https://digitalcommons.uri.edu/chm_facpubs

The University of Rhode Island Faculty have made this article openly available.

Please let us know how Open Access to this research benefits you.

This is a pre-publication author manuscript of the final, published article.

Terms of Use

This article is made available under the terms and conditions applicable towards Open Access

Policy Articles, as set forth in our Terms of Use.

\section{Citation/Publisher Attribution}

Serio, N, \& Levine, M. (2015). Efficient extraction and detection of aromatic toxicants from crude oil and tar balls using multiple cyclodextrin derivatives. Marine Pollution Bulletin, 95(1), 242-247. doi: 10.1016/ j.marpolbul.2015.04.008

Available at: http://dx.doi.org/10.1016/j.marpolbul.2015.04.008

This Article is brought to you for free and open access by the Chemistry at DigitalCommons@URI. It has been accepted for inclusion in Chemistry Faculty Publications by an authorized administrator of DigitalCommons@URI. For more information, please contact digitalcommons-group@uri.edu. 


\section{TITLE PAGE}

TITLE: Efficient Extraction and Detection of Aromatic Toxicants from Crude Oil and Tar Balls using Multiple Cyclodextrin Derivatives

AUTHOR NAMES: Nicole Serio ${ }^{a}$ and Mindy Levine ${ }^{a} *$

$a$ Department of Chemistry, University of Rhode Island, 51 Lower College Road, Kingston, RI

02881; United States; mlevine@chm.uri.edu

*Email: mlevine@chm.uri.edu; Tel: 401-874-4243; Fax: 401-874-5072 


\title{
Efficient Extraction and Detection of Aromatic
}

\section{Toxicants from Crude Oil and Tar Balls using}

\section{Multiple Cyclodextrin Derivatives}

\author{
Nicole Serio and Mindy Levine* \\ Department of Chemistry, University of Rhode Island, 51 Lower College Road, Kingston, RI \\ 02881; mlevine@chm.uri.edu
}

\section{ABSTRACT}

Herein we report the efficient extraction of aromatic analytes from crude oil and tar balls using multiple cyclodextrin derivatives. The known propensity of the cyclodextrins to bind hydrophobic guests in their hydrophobic interiors enhanced the extraction of aromatic analytes from the oil layer to the aqueous layer, with methyl- -cyclodextrin and -cyclodextrin providing the most significant enhancement in extraction efficiencies of aromatic toxicants (69\% aromatic toxicants in aqueous layer in the presence of methyl- -cyclodextrin compared to $47 \%$ in cyclodextrin-free solution for tar ball oil extraction), and provide optimal tunability for developing efficient extraction systems. The cyclodextrin derivatives also promoted efficient energy transfer in the aqueous solutions, with up to $86 \%$ efficient energy transfer observed in the presence of -cyclodextrin compared to $50 \%$ in the absence of cyclodextrin for oil spill oil extraction. Together, this dual function extraction followed by detection system has potential in the development of environmental remediation systems. 


\section{GRAPHICAL ABSTRACT}
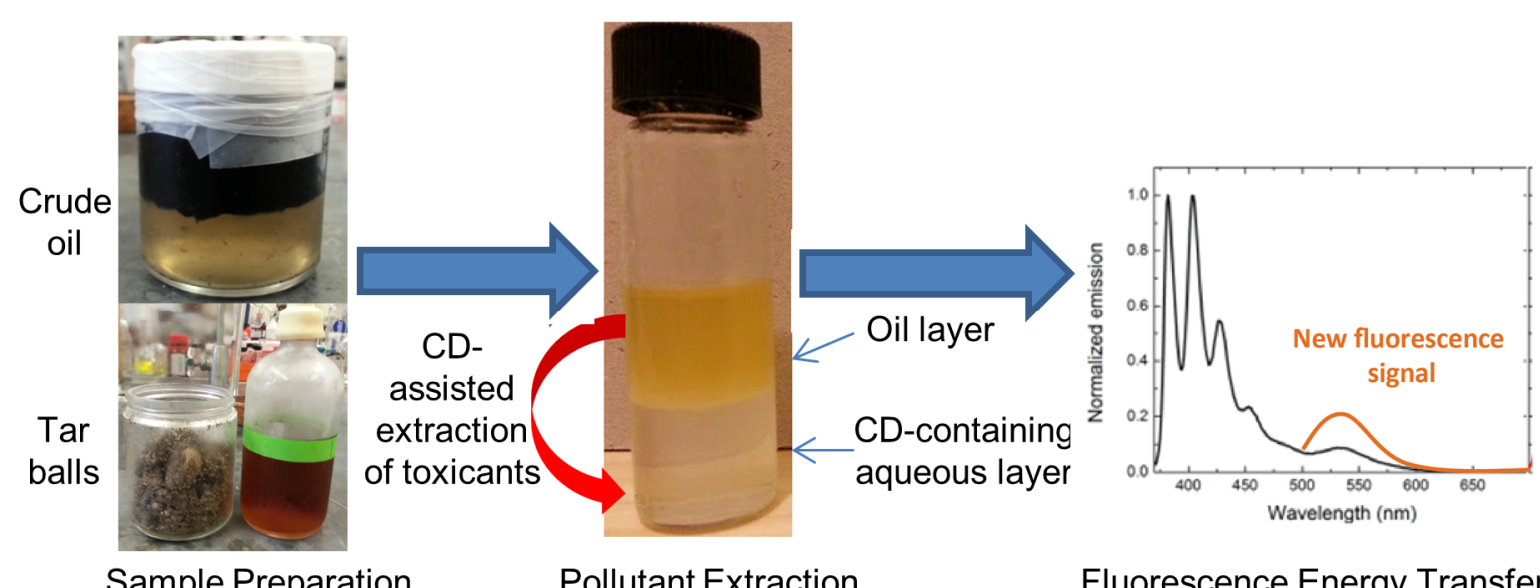

Sample Preparation

Pollutant Extraction

Fluorescence Energy Transfer

\section{KEYWORDS}

tar balls, crude oil, fluorescence detection

\section{INTRODUCTION}

Anthropogenic oil spills such as the Deepwater Horizon oil spill of 2010 highlight a number of unsolved problems in the areas of oil spill cleanup and remediation, ${ }^{1-3}$ efficient detection of oilspill related toxicants in complex environments, ${ }^{4}$ and the monitoring and understanding of longterm effects of oil spills on complex ecosystems. ${ }^{5}$ Current methods used for the cleanup of oil spills include skimming or booning of the oil, ${ }^{6}$ burning oil on the surface of the water, ${ }^{7}$ applying chemical dispersants to facilitate oil dispersion, ${ }^{8}$ and introducing oil-eating bacteria for environmental bioremediation. ${ }^{9}$ Many of these methods suffer from potentially serious drawbacks, including the environmental damage from oil burning, ${ }^{10}$ the unknown toxicity of many dispersants, ${ }^{11}$ and the long-term disruption to the ecosystem from the introduction of nonnative oil-eating bacteria. ${ }^{12}$ In recognition of these problems, newer environmentally-friendly cleanup methods have been developed by several research groups, including the synthesis of new hydrophobic materials, including thermally reduced graphene, a sponge, and porous materials. ${ }^{13-15}$ 
We have developed a new approach for the cleanup of oil spills in marine environments that focuses on the removal of aromatic toxicants such as polycyclic aromatic hydrocarbons (PAHs). ${ }^{16}$ The removal of PAHs is particularly important because many of these compounds are known carcinogens or pro-carcinogens, ${ }^{17}$ including the Class I carcinogen benzo[a]pyrene (Chart 1, compound 3). ${ }^{18}$ This approach uses commercially available, non-toxic -cyclodextrin to bind PAHs and extract them from complex oils. Following the extraction, the PAHs are detected using cyclodextrin-promoted energy transfer to a high quantum yield fluorophore (compound 4); analogous energy transfer has already been established as an efficient method for toxicant detection in multiple complex environments. ${ }^{19-22}$ Other research groups have also reported the use of cyclodextrin derivatives to extract PAHs from complex environments, including from contaminated soil $^{23,24}$ and river sediments. ${ }^{25}$

Previous research in our group focused on the use of -cyclodextrin for the extraction and detection of PAHs from motor oil, vegetable oil, and vacuum pump oil. Shortcomings of this method included the moderate extraction efficiencies observed using -cyclodextrin, as well as the use of commercially available oils rather than oils that had been collected from contaminated marine environments. Oil collected from oil spills (termed "oil spill oil") is more complex than the commercially available oils previously investigated, with a broad distribution of alkanes, aromatic compounds, and insoluble polymeric components. ${ }^{26,27}$ These oils also contain many oxidized PAH derivatives as a result of the exposure of the oil to oxygen-rich environments. ${ }^{28}$ Some crude oil spontaneously forms tar balls, which are oil-containing spheres formed from both oil spills as well as from naturally occurring oil sources. ${ }^{29}$ The degradation and oxidation of toxicants in tar balls has been shown to differ from that of toxicants found in bulk oil samples. ${ }^{30}$ 
Reported herein is the use of a wide variety of cyclodextrin derivatives ( -cyclodextrin, cyclodextrin, methyl- -cyclodextrin, 2-hydroxypropyl- -cyclodextrin (2-HPCD), and cyclodextrin) to extract and detect aromatic toxicants from motor oil, oil spill oil, and tar balls. The extraction and detection efficiencies depend both on the identity of the oil and on the cyclodextrin host. The aromatic small molecules extracted with cyclodextrin include highly toxic PAHs, polar oxidized PAH metabolites, and a variety of other toxicants that have been found in such complex matrices. ${ }^{31}$ The ability of cyclodextrin to extract multiple classes of toxicants simultaneously provides a significant operational advantage in the environmental remediation of polluted marine environments.

\section{MATERIALS AND METHODS}

Materials and Methods. Three oil samples were analyzed: Pennzoil SAE-5W30 motor oil, oil collected from an oil spill site (collected in Louisiana, April 2012), and tar ball oil (collected in Alabama, November 2013). Polycyclic aromatic hydrocarbons (PAHs) 1-3 were purchased from Sigma Aldrich Company and were used as received (Chart 1). These PAHs were intentionally doped into the complex oil samples for the 'doped oil experiments' to measure the ability of cyclodextrins to extract and detect doped PAHs. Highly fluorescent compound $\mathbf{4}$ was synthesized following literature-reported procedures,$^{32}$ and was used in the energy transfer experiments as a high quantum yield energy acceptor. Spectra/Por® 2 Dialysis membranes (Flat Width 45 mm, MWCO 12-14 kD) were purchased from Fisher Scientific and rinsed in deionized water for 15 to 20 minutes, in accordance with the product instructions. Fluorescence measurements were recorded on a Shimadzu RF5301 spectrophotofluorimeter, with a $1.5 \mathrm{~nm}$ excitation slit width and a $1.5 \mathrm{~nm}$ emission slit width. All spectra were integrated versus wavenumber on the $\mathrm{X}$-axis using OriginPro software, version 9.1. 


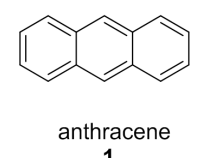

1

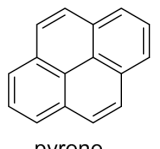

pyrene

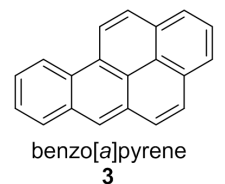

3

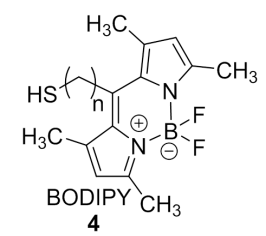

Chart 1. Structures of the analytes (1-3) and fluorophore 4 under investigation

Preparing motor oil, tar ball oil, and oil spill oil for analysis. The motor oil was diluted with an equal volume of $n$-hexanes $(1.25 \mathrm{~mL}$ of motor oil and $1.25 \mathrm{~mL}$ of $n$-hexanes). To prepare the oil spill oil, the oil was diluted in a 1:4 ratio with $n$-hexanes $(0.625 \mathrm{~mL}$ of oil spill oil and $1.875 \mathrm{~mL}$ of $n$-hexanes). The tar balls were prepared by placing a tar ball (weighing $\sim 1.50 \mathrm{~g}$ ) in a mortar and pestle and breaking it up mechanically. Then, $5 \mathrm{~mL}$ of hexanes was added and the tar balls were mixed into the hexanes solution. The solution was then placed in a dialysis bag and placed in a beaker with approximately $400 \mathrm{~mL}$ of $n$-octane. The sample was allowed to dialyze for 3 days until the octane turned brown in color. After this time, the bag was removed and the resulting octane solution was centrifuged at $3000 \mathrm{rpm}$ for 10 minutes. The brown solution was then decanted and stored as the tar ball extract solution. For each experiment, $2.5 \mathrm{~mL}$ of this stock solution was used.

PAH extraction techniques. $2.5 \mathrm{~mL}$ of each oil sample (motor oil, oil spill oil, tar ball extract) was mixed with $20 \mu \mathrm{L}$ of a $1 \mathrm{mg} / \mathrm{mL}$ solution of each analyte (1-3) in tetrahydrofuran (THF), or with $20 \mu \mathrm{L}$ of pure THF (undoped sample). The samples were vigorously shaken by hand for 1 minute, and the oil mixtures were then added to a $2.5 \mathrm{~mL}$ aqueous solution of either a $10 \mathrm{mM}$ in phosphate buffered saline (PBS) cyclodextrin derivative ( -cyclodextrin, cyclodextrin, methyl- -cyclodextrin, 2-hydroxypropyl--cyclodextrin (2-HPCD), and cyclodextrin) or a $0 \mathrm{mM}$ cyclodextrin solution in PBS (control). The mixture was vigorously shaken by hand for 1 minute to ensure thorough mixing. The layers were allowed to sit 
undisturbed for 16-24 hours. The layers were separated and the analytes in each layer, both the doped analytes (1-3) and the undoped samples, were detected by fluorescence spectroscopy with $360 \mathrm{~nm}$ excitation. The analyte fluorescence emission spectrum was integrated versus wavenumber on the $\mathrm{X}$ axis (using OriginPro 9.1 software). The amount of analyte in each layer was quantified as an "analyte comparison" and calculated according to Equation 1:

Analyte comparison $=I_{\text {aqueous }} /\left(\mathrm{I}_{\text {aqueous }}+I_{\text {oil }}\right) \times 100 \%$

where $I_{\text {aquoous }}$ is the integrated emission of the analyte in the aqueous layer and $I_{\text {oil }}$ is the integrated emission of the analyte in the oil layer.

Energy transfer detection techniques. To a $2.5 \mathrm{~mL}$ solution of oil was added $100 \mu \mathrm{L}$ of compound $4(0.1 \mathrm{mg} / \mathrm{mL}$ in THF), $20 \mu \mathrm{L}$ of the analyte of interest $(1.0 \mathrm{mg} / \mathrm{mL}$ in $\mathrm{THF})$ or $20 \mu \mathrm{L}$ of pure THF ("undoped"), and $2.5 \mathrm{~mL}$ of aqueous solution (10 $\mathrm{mM}$ or $0 \mathrm{mM}$ cyclodextrin derivative solution in PBS). The layers were vigorously shaken in a vial for 1 minute and the layers were allowed to separate for 16-24 hours. The layers were separated and each layer was excited at two wavelengths: the analyte excitation wavelength $(360 \mathrm{~nm})$ and the fluorophore excitation wavelength $(460 \mathrm{~nm})$. Each fluorescence emission spectrum was integrated versus wavenumber on the $\mathrm{X}$ axis (using OriginPro 9.1 software). The efficiency of the energy transfer from the analytes to the fluorophore was calculated according to Equation 2:

Energy transfer efficiency $=I_{\mathrm{DA}} / I_{\mathrm{A}} \times 100 \%$

where $I_{\mathrm{DA}}$ is the integration of the fluorophore emission from analyte excitation and $I_{\mathrm{A}}$ is the integrated fluorophore emission from direct excitation.

\section{RESULTS AND DISCUSSION}


PAHs found in oil collected from environmental oil spills have undergone substantial oxidation to a variety of highly polar, oxidized products, including quinones, phenols, and other oxidized species. ${ }^{33}$ Consistent with these reports, when the oil spill oil was mixed with an aqueous buffer solution ( $0 \mathrm{mM}$ cyclodextrin), it demonstrated a high concentration of photophysically active compounds partitioning into the aqueous buffer solution (Figure 1B). Water soluble photophysically active compounds extracted from oils are likely to be oxidized PAH metabolites or other water soluble aromatic moieties, a hypothesis that is supported by ample literature precedent. ${ }^{34-36}$ In contrast, only a negligible concentration of photophysically active compounds partitioned from the motor oil into a cyclodextrin-free aqueous layer, reflecting the lower degree of polar fluorescent metabolites found in that oil (Figure 1A). The oil-water partitioning of tar balls was intermediate between the oil spill oil and the motor oil, with $46 \%$ of the overall fluorescence found in the aqueous buffer layer (Figure 1C). The differential behavior of tar balls compared to oil spill oil can be explained by the different composition of the tar balls - they are enriched in heavier components, such as asphaltenes, that are insoluble in water. ${ }^{37,38}$ The PAHs found in the tar ball's interior are also somewhat protected from oxidation due to their limited interaction with the oxygen-rich environment, whereas the PAHs in oil spill oil are more susceptible to oxidation. ${ }^{39}$

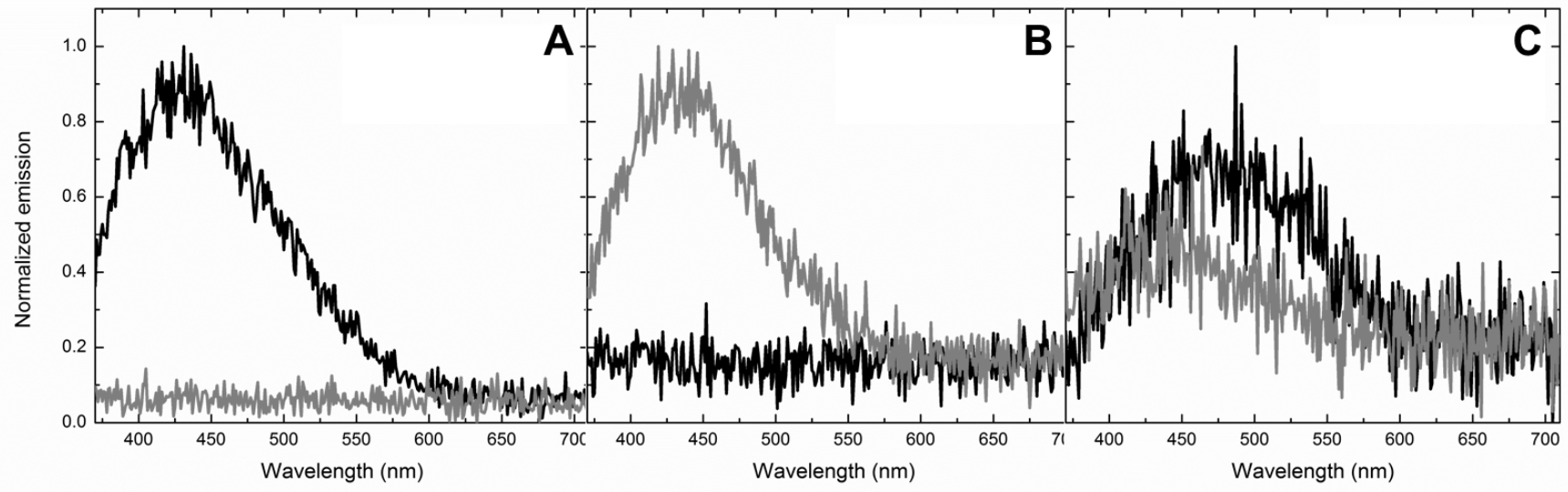


Figure 1. Analyte comparisons in buffer-oil mixtures for (A) motor oil; (B) oil spill oil; and (C) tar ball oil. The black line represents fluorescence of the aqueous layer and the grey line represents fluorescence of the oil layer. All samples were excited at $360 \mathrm{~nm}$.

The addition of cyclodextrin to the aqueous solutions has the potential to alter this partitioning between the aqueous and oil layers, because cyclodextrins have been shown to bind PAHs and other aromatic analytes with high efficiencies. ${ }^{40,41}$ For the motor oil-buffer solutions, the addition of -cyclodextrin and 2-HPCD led to a substantial increase in the amount of photophysically active compounds extracted into the aqueous layer (from $24.0 \%$ in PBS to $33.6 \%$ and $34 \%$ for 2HPCD and -cyclodextrin respectively), which is consistent with the known ability of these cyclodextrins to bind PAHs. Other cyclodextrin derivatives, including $\beta$-cyclodextrin, methyl- $\beta$ cyclodextrin, and $\alpha$-cyclodextrin, have cavity sizes that are too small to bind many PAHs, and their addition had no effect on the oil-water fluorescence ratios (Table 1).

Table 1. Percentage of analyte found in the aqueous layer of oil-buffer solutions with a variety of cyclodextrin derivatives ${ }^{a}$

\begin{tabular}{|l|l|l|l|}
\hline Cyclodextrin derivative & Motor oil & Oil spill oil & Tar ball oil \\
\hline PBS & $24.0 \%$ & $67.2 \%$ & $46.8 \%$ \\
\hline -cyclodextrin & $5.9 \%$ & $59.4 \%$ & $48.6 \%$ \\
\hline -cyclodextrin & $10.3 \%$ & $71.9 \%$ & $44.6 \%$ \\
\hline Me- -cyclodextrin & $4.7 \%$ & $71.7 \%$ & $69.3 \%$ \\
\hline 2-HPCD & $33.6 \%$ & $37.2 \%$ & $65.2 \%$ \\
\hline -cyclodextrin & $33.4 \%$ & $50.9 \%$ & $53.7 \%$ \\
\hline
\end{tabular}

a All analyte comparisons were calculated using Equation 1, with undoped oil samples. All reported results represent an average of at least 3 trials.

For the oil spill oil-aqueous mixtures, the addition of both 2-HPCD and $\gamma$-cyclodextrin increased the fluorescence of both the oil layer and the aqueous layer. However, the fluorescence 
of the oil layer increased to a much greater extent (6.95-fold) compared to that of the aqueous layer (2.42-fold increase) (Figure 2), leading to an overall decrease in the percentage of fluorescently active compounds found in the aqueous layer. These fluorescence increases can be explained by the cyclodextrin binding a variety of PAHs and PAH metabolites in both the aqueous and oil phases; in each case, binding of the fluorescent small molecules leads to a noticeable fluorescence increase through the elimination of non-radiative decay pathways. ${ }^{42}$

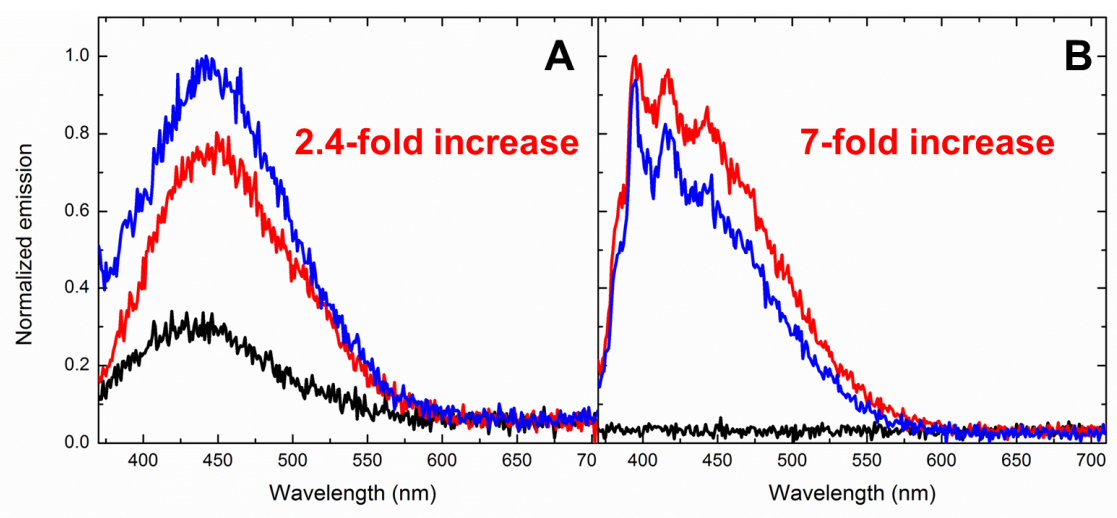

Figure 2. Changes in the fluorescence in oil spill oil-buffer solutions with the addition of various cyclodextrins in the (A) aqueous layer; and (B) oil layer. The black line shows the fluorescence in a PBS-oil solution (no cyclodextrin), the blue line shows the fluorescence in a -cyclodextrinoil solution, and the red line shows the fluorescence in a 2-HPCD-oil solution. These results are representative results of 3 independent trials. (Color figure requested online and in print)

For the tar ball oil-buffer mixtures, the addition of all cyclodextrin derivatives led to modest enhancements in the fluorescence ratios of the aqueous layer, with the exception of cyclodextrin which showed no change in the extraction efficiencies. These results indicate that the cyclodextrins are moderately effective in extracting photophysically active analytes from the crude tar ball solution. The larger cyclodextrins likely extract PAHs via hydrophobic encapsulation of the hydrophobic PAHs, analogous to what is observed with motor oil samples 
and what we reported in our previous publication. ${ }^{16}$ However, the addition of the smaller cyclodextrins also led to an increase in the percentage of fluorescence found in the aqueous layer, even though such cyclodextrins lack sufficient steric bulk to encapsulate PAHs in their hydrophobic cavities. These cyclodextrins are likely effecting fluorescence increases by binding polar PAH analytes via hydrogen bond formation $;^{43}$ this hydrogen bonding allows analytes that are too large to bind in the cyclodextrin interior to associate with the cyclodextrins, thereby enabling enhanced extraction into the aqueous layer.

Following the efficient extraction of PAHs from a variety of complex oils using cyclodextrin derivatives, the ability of the newly extracted PAHs to participate in cyclodextrin-promoted energy transfer in the aqueous layer was assayed. This energy transfer requires that fluorophore 4 partition efficiently into the aqueous layer. The percentage of fluorophore emission in the aqueous layer was measured for all oil-cyclodextrin combinations, and found to be particularly efficient for methyl- -cyclodextrin containing solutions (Figure 3). This high efficiency points to a high degree of steric and electronic compatibility between methyl--cyclodextrin and fluorophore 4. Notably, some degree of fluorescence emission from fluorophore 4 was found in the aqueous layer for all oil-cyclodextrin combinations, indicating the potential for efficient energy transfer in all cases. 


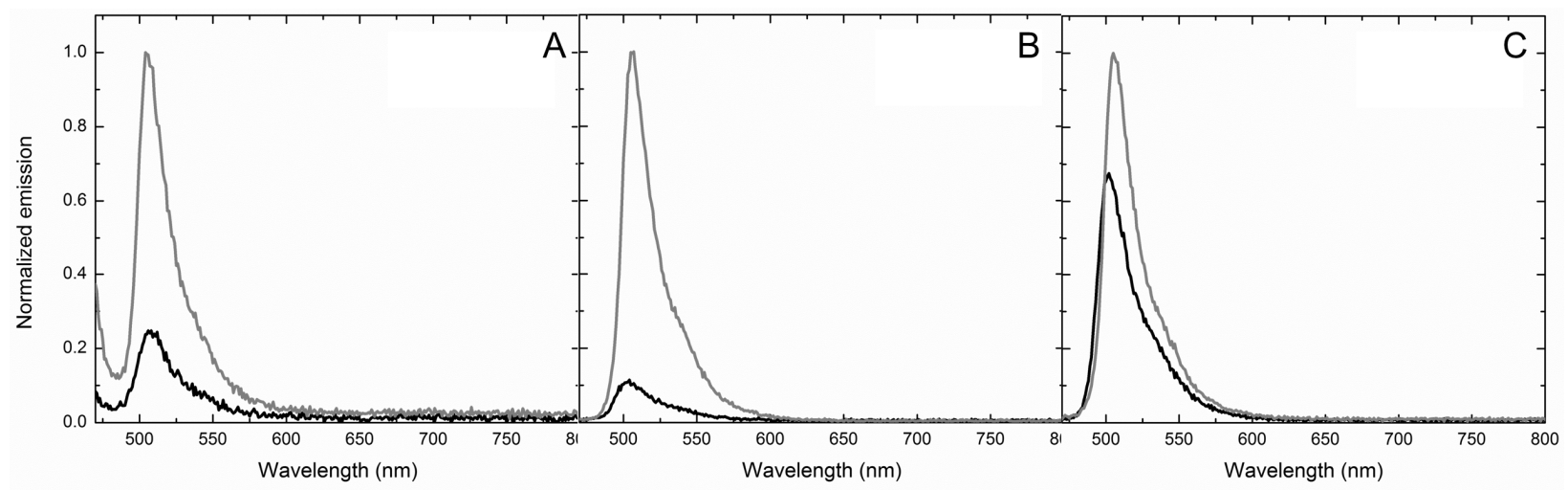

Figure 3. Fluorophore 4 emission in aqueous-oil mixtures for (A) motor oil; (B) oil spill oil; and (C) tar ball oil. The black line represents fluorescence of the aqueous layer without cyclodextrin and the grey line represents fluorescence of the aqueous layer with $10 \mathrm{mM}$ of methyl- cyclodextrin. All samples were excited at $460 \mathrm{~nm}$.

Energy transfer in the aqueous layer was measured for all cyclodextrin-oil combinations, and some key results are summarized in Tables 2-5.

Table 2. Energy transfer efficiencies in the undoped aqueous extracts ${ }^{a}$

\begin{tabular}{|l|l|l|l|}
\hline $\begin{array}{l}\text { Cyclodextrin } \\
\text { derivative }\end{array}$ & Motor oil & Oil spill oil & Tar ball oil \\
\hline PBS & $b$ & $50.0 \%$ & $23.9 \%$ \\
\hline -cyclodextrin & $36.8 \%$ & $51.8 \%$ & $33.3 \%$ \\
\hline -cyclodextrin & $45.9 \%$ & $29.5 \%$ & $20.4 \%$ \\
\hline Me- -cyclodextrin & $35.9 \%$ & $24.1 \%$ & $31.6 \%$ \\
\hline 2-HPCD & $74.4 \%$ & $85.7 \%$ & $34.5 \%$ \\
\hline -cyclodextrin & $73.0 \%$ & $86.4 \%$ & $28.5 \%$ \\
\hline
\end{tabular}

$a$ All values represent an average of at least 3 trials

$b$ No energy transfer peak was observed

Table 3. Energy transfer efficiencies in the aqueous extracts doped with analyte $\mathbf{1}^{a}$ 


\begin{tabular}{|l|l|l|l|}
\hline $\begin{array}{l}\text { Cyclodextrin } \\
\text { derivative }\end{array}$ & Motor oil & Oil spill oil & Tar ball oil \\
\hline PBS & $9.0 \%$ & $78.7 \%$ & $24.8 \%$ \\
\hline -cyclodextrin & $b$ & $30.2 \%$ & $32.5 \%$ \\
\hline -cyclodextrin & $46.2 \%$ & $34.4 \%$ & $23.3 \%$ \\
\hline Me- -cyclodextrin & $38.7 \%$ & $26.1 \%$ & $29.5 \%$ \\
\hline 2-HPCD & $b$ & $80.1 \%$ & $26.6 \%$ \\
\hline -cyclodextrin & $71.0 \%$ & $77.2 \%$ & $28.1 \%$ \\
\hline
\end{tabular}

$a$ All values represent an average of at least 3 trials

$b$ No energy transfer peak was observed

Table 4. Energy transfer efficiencies in the aqueous extracts doped with analyte $\mathbf{2}^{a}$

\begin{tabular}{|l|l|l|l|}
\hline $\begin{array}{l}\text { Cyclodextrin } \\
\text { derivative }\end{array}$ & Motor oil & Oil spill oil & Tar ball oil \\
\hline PBS & $80.5 \%$ & $68.8 \%$ & $26.2 \%$ \\
\hline -cyclodextrin & $57.7 \%$ & $28.3 \%$ & $32.9 \%$ \\
\hline -cyclodextrin & $49.2 \%$ & $34.2 \%$ & $23.6 \%$ \\
\hline Me- -cyclodextrin & $38.1 \%$ & $28.2 \%$ & $29.7 \%$ \\
\hline 2-HPCD & $85.4 \%$ & $73.8 \%$ & $27.1 \%$ \\
\hline -cyclodextrin & $71.0 \%$ & $80.1 \%$ & $29.3 \%$ \\
\hline
\end{tabular}

$a$ All values represent an average of at least 3 trials

Table 5. Energy transfer efficiencies in the aqueous extracts doped with analyte $\mathbf{3}^{a}$

\begin{tabular}{|l|l|l|l|}
\hline $\begin{array}{l}\text { Cyclodextrin } \\
\text { derivative }\end{array}$ & Motor oil & Oil spill oil & Tar ball oil \\
\hline PBS & $54.6 \%$ & $62.6 \%$ & $29.7 \%$ \\
\hline -cyclodextrin & $64.6 \%$ & $38.1 \%$ & $30.5 \%$ \\
\hline -cyclodextrin & $68.3 \%$ & $32.1 \%$ & $24.7 \%$ \\
\hline Me- -cyclodextrin & $38.7 \%$ & $23.5 \%$ & $31.6 \%$ \\
\hline
\end{tabular}




\begin{tabular}{|l|l|l|l|}
\hline 2 -HPCD & $85.6 \%$ & $69.5 \%$ & $28.6 \%$ \\
\hline -cyclodextrin & $72.0 \%$ & $99.4 \%$ & $30.5 \%$ \\
\hline
\end{tabular}

$a$ All values represent an average of at least 3 trials

For oil spill oil, the observed energy transfer efficiency with undoped samples in the absence of any cyclodextrin was fairly high, and the addition of -cyclodextrin and methyl- -cyclodextrin led to decreases in the observed energy transfer efficiencies (energy transfer efficiencies of 30\% and $24 \%$ for -cyclodextrin and methyl--cyclodextrin, respectively, compared to $50 \%$ in the absence of any cyclodextrin) (Table 2). The addition of larger cyclodextrins (i.e. 2-HPCD and cyclodextrin) caused a substantial enhancement in the observed affinities. The large degree of cyclodextrin-free energy transfer is consistent with our previously reported results that showed cyclodextrin-free association in many complex environments. ${ }^{19}$ In these aqueous extracts, PAH metabolites likely associate with fluorophore 4 via a combination of hydrophobic binding (between the aromatic portions of the metabolites and the aromatic moieties of the fluorophore) and hydrogen bonding (between the hydroxyl and carbonyl moieties of the metabolites and the thiol and charged portions of the fluorophore); this close association is responsible for the observed cyclodextrin-free energy transfer.

For oil collected from tar balls, a modest energy transfer efficiency in the cyclodextrin-free solution was observed in undoped samples, and this efficiency was somewhat enhanced by the addition of most cyclodextrin derivatives by 8-10 percentage points (Table 2), with only cyclodextrin leading to a slight decrease in the energy transfer efficiencies. The most likely explanation for this scenario is that cyclodextrins facilitate the association of the aromatic toxicants with fluorophore 4. This facilitated association can either occur via the formation of a ternary complex in the cyclodextrin cavity (as has been demonstrated for -cyclodextrin ${ }^{20-22,44,45}$ 
and $2-\mathrm{HPCD}^{46},{ }^{47}$ ), or via association of one of the two energy transfer partners outside the cyclodextrin cavity (a more likely scenario for the smaller cyclodextrin derivatives).

In aqueous extracts from motor oil, the degree of cyclodextrin-free energy transfer varied depending on the identity of the doped analyte, with analytes $\mathbf{2}$ and $\mathbf{3}$ demonstrating substantially higher degrees of cyclodextrin-free energy transfer compared to analyte $\mathbf{1}$. This is consistent with our previously reported results that demonstrated that analytes with large hydrophobic surface areas are most likely to engage in cyclodextrin-free association and cyclodextrin-independent energy transfer. ${ }^{19}$ The energy transfer efficiencies were most improved by the addition of 2HPCD and -cyclodextrin, with $73 \%$ and $74 \%$ efficiencies observed using -cyclodextrin and 2HPCD, respectively. These results are consistent with the known ability of these cyclodextrins to form ternary complexes that promote proximity-induced energy transfer. ${ }^{48}$

The results in Table 2 highlight the ability of cyclodextrin to remove aromatic toxicants from both oil spill oil and tar ball oil. These experiments, conducted without doping a particular PAH into the complex mixture, involve the cyclodextrins extracting a wide range of toxicants from the complex oils, including PAHs, PAH metabolites, and other aromatic moieties. Overall, the results reported herein highlight the potential of cyclodextrin derivatives to promote the efficient extraction of small-molecule toxicants from oil spills, as well as their subsequent detection via energy transfer to a high quantum yield fluorophore. This system has a number of notable advantages, including:

(1) In contrast to our previously reported results that demonstrated modest extraction efficiencies using -cyclodextrin to extract PAHs from motor oil, vegetable oil, and vacuum pump oil, we report herein substantially improved extraction efficiencies using a variety of cyclodextrin derivatives to extract aromatic toxicants from oil spill oil and tar ball oil, with up to $72 \%$ of the aromatic toxicants found in the cyclodextrin-containing aqueous layer, compared to 
our previously reported best of $34 \%$ aromatic analytes in -cyclodextrin-containing aqueous layer extracted from motor oil. Oil collected directly from oil spill sites and oil isolated from tar balls have different physicochemical profiles compared to motor oil, vegetable oil, and vacuum pump oil, as a result of the weathering process that promotes substantial oxidation of the aromatic toxicants. ${ }^{5}$ Environmental remediation of oil spill oil and tar ball oil from polluted marine environments is substantially more relevant for environmental disaster efforts than the remediation of commercially available oils, and the results reported herein indicate that using a variety of cyclodextrin derivatives enables the efficient extraction of toxicants from these complex oils.

(2) The cyclodextrin-based extraction followed by detection system reported herein provides a rapid method to remove toxicants from oil spills and to confirm that photophysically active analytes were removed via fluorescence energy transfer, which is a useful tool in disaster response efforts. In many oil spill situations, the precise identification of each toxicants is less crucial than the ability to remove as many toxicants as possible as quickly as possible and confirm such removal. Using cyclodextrin derivatives to enhance the extraction of photophysically active compounds from the oil layer to the aqueous layer, as demonstrated herein, provides a practical method for such environmental detoxification, and monitoring the overall fluorescence of the extracted analytes provides a rapid method to assay the efficacy of such detoxification procedures.

\section{CONCLUSION}

In conclusion, the results reported herein demonstrate that cyclodextrin-based systems can be used for the efficient extraction and detection of aromatic toxicants from real-world oil samples collected at the sites of oil spills. The system uses a number of commercially-available, non-toxic cyclodextrin derivatives to optimize extraction and detection procedures for each oil sample 
investigated, and demonstrate that our previously-reported results are generally applicable for the cleanup of oil-contaminated marine environments. These results also pointed to the potential of using multiple cyclodextrins simultaneously for the cleanup of a single oil system, with the cyclodextrins that are optimal for extraction of PAHs, binding of the fluorophore, and promotion of efficient energy transfer combined into a single high-performing, multi-cyclodextrin system. Research in this direction is currently underway in our group, and the results to date support this idea. The full results will be reported in due course.

\section{ASSOCIATED CONTENT}

Supporting Information. Detailed experimental procedures, synthetic procedures for the synthesis of fluorophore $\mathbf{4}$, all summary tables and summary figures for all analyte-oilcyclodextrin combinations. This material is available free of charge via the Internet .

\section{AUTHOR INFORMATION}

\section{Corresponding Author}

*Department of Chemistry, University of Rhode Island, 51 Lower College Road, Kingston, RI 02881; tel: 401-874-4243; fax: 401-874-5072; email: mlevine@chm.uri.edu

\section{Author Contributions}

The manuscript was written through contributions of all authors, and all authors have given approval to the final version of the manuscript.

\section{Funding Sources}

This research was supported by a grant from the Gulf of Mexico Research Initiative.

\section{REFERENCE}


${ }^{1}$ Gohlke, J. M.; Doke, D.; Tipre, M.; Leader, M.; Fitzgerald, T. A Review of Seafood Safety after the Deepwater Horizon Blowout. Environ. Health Perspectives 2011, 119, 1062-1069.

${ }^{2}$ Anastas, P. T.; Sonich-Mullin, C.; Fried, B. Designing Science in a Crisis: the Deepwater Horizon Oil Spill. Environ. Sci. Technol. 2010, 44, 9250-9251.

${ }^{3}$ McNutt, M. K.; Chu, S.; Lubchenco, J.; Hunter, T.; Dreyfus, G.; Murawski, S. A.; Kennedy, D. M. Applications of Science and Engineering to Quantify and Control the Deepwater Horizon Oil Spill. Proc. Natl. Acad. Sci. U.S.A. 2012, 109, 20222-20228.

${ }^{4}$ Radovic, J. R.; Rial, D.; Lyons, B. P.; Harman, C.; Vinas, L.; Beiras, R.; Readman, J. W.; Thomas, K. V.; Bayona, J. M. Post-Incident Monitoring to Evaluate Environmental Damage from Shipping Incidents: Chemical and Biological Assessments. J. Environ. Management 2012, $109,136-153$.

${ }^{5}$ Yim, U. H.; Kim, M.; Ha, S. Y.; Kim, S.; Shim, W. J. Oil Spill Environmental Forensics: the Hebei Spirit Oil Spill Case. Environ. Sci. Technol. 2012, 46, 6431-6437.

${ }^{6}$ Broje, V.; Keller, A. A. Improved Mechanical Oil Spill Recovery Using an Optimized Geometry for the Skimmer Surface. Environ. Sci. Technol. 2006, 40, 7914-7918.

${ }^{7}$ Sneddon, J.; Hardaway, C.; Bobbadi, K. K.; Beck, J. N. A Study of a Crude Oil Spill Site for Selected Metal Concentrations Remediated by a Controlled Burning in Southwest Louisiana. Microchem. J. 2006, 82, 8-16.

${ }^{8}$ Saha, A.; Nikova, A.; Venkataraman, P.; John, V. T.; Bose, A. Oil Emulsification Using Surface-Tunable Carbon Black Particles. ACS Appl. Mater. Interfaces 2013, 5, 3094-3100. 
${ }^{9}$ Yang, S.-Z.; Jin, H.-J.; Wei, Z.; He, R.-X.; Ji, Y.-J.; Li, X.-M.; Yu, S.-P. Bioremediation of Oil Spills in Cold Environments: a Review. Pedosphere 2009, 19, 371-381.

${ }^{10}$ Prendergast, D. P.; Gschwend, P. M. Assessing the Performance and Cost of Oil Spill Remediation Technologies. J. Cleaner Production 2014, 78, 233-242.

${ }^{11}$ Wise, J.; Wise, J. P., Sr. A Review of the Toxicity of Chemical Dispersants. Rev. Environ. Health 2011, 26, 281-300.

${ }^{12}$ Ahluwalia, A. K.; Sekhon, B. S. Bioremediation: Current Scenario and a Necessity in Immediate Future. Environ. Sci. Indian J. 2012, 7, 349-364.

${ }^{13}$ Iqbal, M. Z.; Abdala, A. A. Oil Spill Cleanup Using Graphene. Environ. Sci. Pollution Res. 2013, 20, 3271-3279.

${ }^{14}$ Wang, C.-F.; Lin, S.-J. Robust Superhydrophobic/Superoleophilic Sponge for Effective Continuous Absorption and Expulsion of Oil Pollutants from Water. ACS Appl. Mater. Interfaces 2013, 5, 8861-8864.

${ }^{15}$ Peng, L.; Li, H.; Zhang, Y.; Su, J.; Yu, P.; Luo, Y. A Superhydrophobic 3D Porous Material for Oil Spill Cleanup. RSC Advances 2014, 4, 46470-46475.

${ }^{16}$ Serio, N.; Chanthalyma, C.; Prignano, L.; Levine, M. Cyclodextrin-Enhanced Extraction and Energy Transfer of Carcinogens in Complex Oil Environments. ACS Appl. Mater. Interfaces 2013, 5, 11951-11957. 
${ }^{17}$ Jarvis, I. W. H.; Dreij, K.; Mattsson, A.; Jernstroem, B.; Stenius, U. Interactions Between Polycyclic Aromatic Hydrocarbons in Complex Mixtures and Implications for Cancer Risk Assessment. Toxicol. 2014, 321, 27-39.

${ }^{18}$ Nebert, D. W.; Shi, Z.; Galvez-Peralta, M.; Uno, S.; Dragin, N. Oral Benzo[a]pyrene: Understanding Pharmacokinetics, Detoxication, and Consequences-Cyp1 Knockout Mouse Lines as a Paradigm. Molec. Pharmacol. 2013, 84, 304-313.

${ }^{19}$ Serio, N.; Prignano, L.; Peters, S.; Levine, M. Detection of Medium-Sized Polycyclic Aromatic Hydrocarbons via Fluorescence Energy Transfer. Polycyclic Aromatic Compounds 2014, 34, 561-572.

${ }^{20}$ Mako, T.; Marks, P.; Cook, N.; Levine, M. Fluorescent Detection of Polycyclic Aromatic Hydrocarbons in Ternary Cyclodextrin Complexes. Supramol. Chem. 2012, 24, 743-747.

${ }^{21}$ Serio, N.; Miller, K.; Levine, M. Efficient Detection of Polycyclic Aromatic Hydrocarbons and Polychlorinated Biphenyls via Three-Component Energy Transfer. Chem. Commun. 2013, $49,4821-4823$.

${ }^{22}$ Serio, N.; Chanthalyma, C.; Prignano, L.; Levine, M. Cyclodextrin-Promoted Energy Transfer for Broadly Applicable Small-Molecule Detection. Supramol. Chem. 2014, 26, 714721.

${ }^{23}$ Sanchez-Trujillo, M. A.; Morillo, E.; Villaverde, J.; Lacorte, S. Comparative Effects of Several Cyclodextrins on the Extraction of PAHs from an Aged Contaminated Soil. Environ. Pollution 2013, 178, 52-58. 
${ }^{24}$ Petitgirard, A.; Djehiche, M.; Persello, J.; Fievet, P.; Fatin-Rouge, N. PAH Contaminated Soil Remediation by Reusing an Aqueous Solution of Cyclodextrins. Chemosphere 2009, 75, 714-718.

${ }^{25}$ Schulze, T.; Seiler, T.-B.; Streck, G.; Braunbeck, T.; Hollert, H. Comparison of Different Exhaustive and Biomimetic Extraction Techniques for Chemical and Biological Analysis of Polycyclic Aromatic Compounds in River Sediments. J. Soils Sediments 2012, 12, 1419-1434.

${ }^{26}$ Wang, Z.; Fingas, M. Oil and Petroleum Product Fingerprinting Analysis by Gas Chromatographic Techniques. Chromatographic Sci. Series 2006, 93, 1027-1101.

${ }^{27}$ Panda, S. K.; Andersson, J. T.; Schrader, W. Mass-Spectrometric Analysis of Complex Volatile and Nonvolatile Crude Oil Components: A Challenge. Anal. Bioanal. Chem. 2007, 389, 1329-1339.

${ }^{28}$ Filatov, D. A.; Gulaya, E. V.; Svarovskaya, L. I.; Altunina, L. K. Biochemical Oxidation of High-Viscosity Oil by Indigenous Soil Microflora. Petroleum Chem. 2013, 53, 59-64.

${ }^{29}$ Hostettler, F. D.; Rosenbauer, R. J.; Lorenson, T. D.; Dougherty, J. Geochemical Characterization of Tarballs on Beaches along the California Coast. Part I- Shallow Seepage Impacting the Santa Barbara Channel Islands, Santa Cruz, Santa Rosa and San Miguel. Org. Geochem. 2004, 35, 725-746.

${ }^{30}$ Pendergraft, M. A.; Rosenheim, B. E. Varying Relative Degradation Rates of Oil in Different Forms and Environments Revealed by Ramped Pyrolysis. Environ. Sci. Technol. 2014, 48, 10966-10974. 
${ }^{31}$ Kang, H.-J.; Lee, S.-Y.; Roh, J.-Y.; Yim, U. H.; Shim, W. J.; Kwon, J.-H. Prediction of Ecotoxicity of Heavy Crude Oil: Contribution of Measured Components. Environ. Sci. Technol. 2014, 48, 2962-2970.

${ }^{32}$ Shepherd, J. L.; Kell, A.; Chung, E.; Sinclar, C. W.; Workentin, M. S.; Bizzotto, D. Selective Reductive Desorption of a SAM-Coated Gold Electrode Revealed Using Fluorescence Microscopy. J. Am. Chem. Soc. 2004, 126, 8329-8335.

${ }^{33}$ Ruddy, B. M.; Huettel, M.; Kostka, J. E.; Lobodin, V. V.; Bythell, B. J.; McKenna, A. M.; Aeppli, C.; Reddy, C. M.; Nelson, R. K.; Marshall, A. G.; Rodgers, R. P. Targeted Petroleomics: Analytical Investigation of Macondo Well Oil Oxidation Products from Pensacola Beach. Energy \& Fuels 2014, 28, 4043-4050.

${ }^{34}$ Noh, S. R.; Cheong, H.-K.; Ha, M.; Eom, S.-Y.; Kim, H.; Choi, Y.-H.; Paek, D. Oxidative Stress Biomarkers in Long-Term Participants in Clean-Up Work After the Hebei Spirit Oil Spill. Sci. Total Environ. 2015, 515-516, 207-214.

${ }^{35}$ Troisi, G.; Borjesson, L.; Bexton, S.; Robinson, I. Biomarkers of Polycyclic Aromatic Hydrocarbon (PAH)-Associated Hemolytic Anemia in Oiled Wildlife. Environ. Res. 2007, 105, 324-329.

${ }^{36}$ Troisi, G. M.; Bexton, S.; Robinson, I. Polyaromatic Hydrocarbon and PAH Metabolite Burdens in Oiled Common Guillemots (Uria aalge) Stranded on the East Coast of England (2001-2002). Environ. Sci. Technol. 2006, 40, 7938-7943. 
${ }^{37}$ Kiruri, L. W.; Dellinger, B.; Lomnicki, S. Tar Balls from Deep Water Horizon Oil Spill: Environmentally Persistent Free Radicals (EPFR) Formation During Crude Weathering. Environ. Sci. Technol. 2013, 47, 4220-4226.

${ }^{38}$ Savage, M.; Ward, C. H. Chemical Characteristics of Laboratory Produced Tarballs. Marine Pollution Bull. 1984, 15, 174-178.

${ }^{39}$ Goodman, R. Tar Balls: The End State. Spill Sci. Technol. Bull. 2003, 8, 117-121.

${ }^{40}$ Morillo, E.; Sanchez-Trujillo, M. A.; Moyano, J. R.; Villaverde, J.; Gomez-Pantoja, M. E.; Perez-Martinez, J. I. Enhanced Solubilisation of Six PAHs by Three Synthetic Cyclodextrins for Remediation Applications: Molecular Modelling of the Inclusion Complexes. PLos One 2012, 7 , e44137.

${ }^{41}$ Blanford, W. J.; Gao, H.; Dutta, M.; Ledesma, E. B. Solubility Enhancement and QSPR Correlations for Polycyclic Aromatic Hydrocarbons Complexation with , , and Cyclodextrins. J. Inclusion Phenom. Macrocyclic Chem. 2014, 78, 415-427.

${ }^{42}$ Ogoshi, T.; Harada, A. Chemical Sensors Based on Cyclodextrin Derivatives. Sensors 2008, $8,4961-4982$.

${ }^{43}$ Hardie, M. J. Hydrogen Bonded Network Structures Constructed from Molecular Hosts. Structure and Bonding 2004, 111, 139-174.

${ }^{44}$ Nazarov, V. B.; Avakyan, V. G.; Vershinnikova, T. G.; Alfimov, M. V.; Rudyak, V. Y. Inclusion Complexes Naphthalene- -Cyclodextrin-Adamantane and Naphthalene- -Cyclodextrino-Carborane: the Structure and Luminescence Properties. Russ. Chem. Bull. 2012, 61, 665-667. 
${ }^{45}$ Garcia Rio, L.; Fernandez-Rosas, J.; Pessego, M.; Cepeda, M.; Basilio, N.; Parajo, M.; Rodriguez-Dafonte, P. -Cyclodextrin Modulates Chemical Reactivity by Multiple Complexation. Org. Biomol. Chem. 2014, Ahead of Print, DOI: 10.1039/C4OB02113D

${ }^{46}$ Asbahr, A. C. C.; Franco, L.; Barison, A.; Silva, C. W. P.; Ferraz, H. G.; Rodrigues, L. N. C. Binary and Ternary Inclusion Complexes of Finasteride in HP CD and Polymers: Preparation and Characterization. Bioorg. Med. Chem. 2009, 17, 2718-2723.

${ }^{47}$ Zoeller, T.; Dressman, J. B.; Klein, S. Application of a Ternary HP- -CD-Complex Approach to Improve the Dissolution Performance of a Poorly Soluble Weak Acid Under Biorelevant Conditions. Int. J. Pharmaceutics 2012, 430, 176-183.

${ }^{48}$ Hamai, S. Complex Formation of Tetrakis(4-sulfonatophenyl)porphyrin with -Cyclodextrin, Phenylalanine, and Tryptophan in Aqueous Solution. J. Inclusion Phenom. Macrocyclic Chem. 2010, 67, 471-481. 